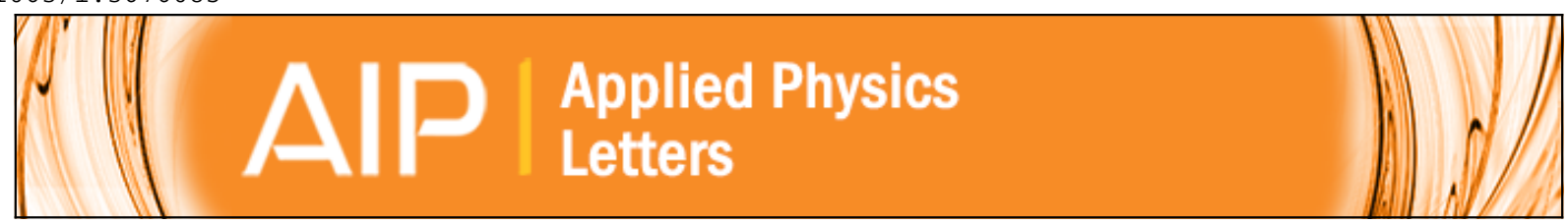

\title{
Improvement of temperature-stability in a quantum well laser with asymmetric barrier layers
}

Alexey E. Zhukov, Natalia V. Kryzhanovskaya, Fedor I. Zubov, Yuri M. Shernyakov, Mikhail V. Maximov, Elizaveta S. Semenova, Kresten Yvind, and Levon V. Asryan

Citation: Applied Physics Letters 100, 021107 (2012); doi: 10.1063/1.3676085

View online: http://dx.doi.org/10.1063/1.3676085

View Table of Contents: http://scitation.aip.org/content/aip/journal/apl/100/2?ver=pdfcov

Published by the AIP Publishing

\section{Articles you may be interested in}

Improvement of characteristics of InGaN-based laser diodes with undoped InGaN upper waveguide layer J. Appl. Phys. 112, 113105 (2012); 10.1063/1.4768287

$1.3 \mathrm{~m}$ Ga 0.11 In 0.89 As $0.24 \mathrm{P} 0.76$ Ga 0.27 In 0.73 As 0.67 P 0.33 compressive-strain multiple quantum well with $\mathrm{n}$-type modulation-doped GalnP intermediate-barrier laser diodes

J. Vac. Sci. Technol. B 25, 1382 (2007); 10.1116/1.2757183

Room-temperature operation of electrically pumped quantum-cascade microcylinder lasers

Appl. Phys. Lett. 80, 4094 (2002); 10.1063/1.1484246

InAs/GaAs quantum dot lasers with InGaP cladding layer grown by solid-source molecular-beam epitaxy Appl. Phys. Lett. 80, 535 (2002); 10.1063/1.1445269

Low-threshold-current 1.32-m GalnNAs/GaAs single-quantum-well lasers grown by molecular-beam epitaxy Appl. Phys. Lett. 79, 3386 (2001); 10.1063/1.1418455

\section{AlP Re-register for Table of Content Alerts}




\title{
Improvement of temperature-stability in a quantum well laser with asymmetric barrier layers
}

\author{
Alexey E. Zhukov, ${ }^{1, a)}$ Natalia V. Kryzhanovskaya, ${ }^{1, b)}$ Fedor I. Zubov, ${ }^{1, c)}$ \\ Yuri M. Shernyakov, ${ }^{2, d)}$ Mikhail V. Maximov, ${ }^{2, e)}$ Elizaveta S. Semenova, ${ }^{3, f)}$ \\ Kresten Yvind, ${ }^{3, g)}$ and Levon V. Asryan ${ }^{4, h)}$ \\ ${ }^{1}$ Department of Nanotechnology, St. Petersburg Academic University, St. Petersburg 194021, Russia \\ ${ }^{2}$ Ioffe Physico-Technical Institute, St. Petersburg 194021, Russia \\ ${ }^{3}$ DTU Fotonik, Technical University of Denmark, Kgs. Lyngby DK-2800, Denmark \\ ${ }^{4}$ Virginia Polytechnic Institute and State University, Blacksburg, Virginia 24061, USA
}

(Received 2 December 2011; accepted 20 December 2011; published online 10 January 2012)

\begin{abstract}
We fabricated and tested a quantum well laser with asymmetric barrier layers. Such a laser has been proposed earlier to suppress bipolar carrier population in the optical confinement layer and thus to improve temperature-stability of the threshold current. As compared to the conventional reference laser structure, our laser with asymmetric barrier layers demonstrates reduced internal optical loss, lower threshold current density at elevated temperatures, and higher characteristic temperature (143 vs. $99 \mathrm{~K}$ at $20^{\circ} \mathrm{C}$ ). (C) 2012 American Institute of Physics. [doi:10.1063/1.3676085]
\end{abstract}

An important parameter of diode lasers is the characteristic temperature $T_{0}$, which describes the temperaturesensitivity of the threshold current. High $T_{0}$ is required for stable operation under variable ambient conditions as well as for minimization of self-heating effects at high operating powers. Ideally, the room-temperature value of $T_{0}$ in a quantum well (QW) laser can be as high as $300 \mathrm{~K} .{ }^{1}$ However, in the conventional QW lasers, the electron-hole recombination occurs not only in QWs but also outside the active region, which may significantly increase the threshold current and reduce its temperature stability. Electron-hole recombination in the optical confinement layer (OCL) is particularly important in lasers with broad OCL, which are used for highpower operation, ${ }^{2}$ and in lasers with small localization energy of carriers in a QW.

The parasitic recombination in the OCL can be suppressed and the characteristic temperature can be enhanced to a certain extent by using a larger bandgap OCL in combination with larger bandgap cladding layers. ${ }^{3,4}$ However, such a method is not always applicable due to limitations of lattice-matched growth. Alternatively, the parasitic recombination in the OCL can be suppressed in a laser structure with two asymmetric barrier layers (ABLs) (one on each side of the active region) as it has been proposed in Ref. 5. Since the ABLs may represent thin pseudomorphic layers, this approach makes the laser design more flexible. In the ABL laser, while the electrons injected from the n-cladding layer easily pass over the $\mathrm{n}$-side $\mathrm{ABL}$ on their way to the $\mathrm{QW}$, the holes injected from the p-cladding layer ideally should not pass over or tunnel through that ABL. Similarly, the p-side ABL should be easily overcome by the holes injected from

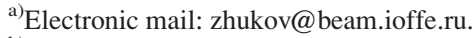

${ }^{\text {b) }}$ Electronic mail: kryj@mail.ioffe.ru.

${ }^{c)}$ Electronic mail: fedyazu@mail.ru.

d)Electronic mail: yuri.shernyakov@mail.ioffe.ru.

${ }^{\mathrm{e})}$ Electronic mail: maximov@beam.ioffe.ru.

${ }^{\mathrm{f}}$ Electronic mail: esem@fotonik.dtu.dk.

g)Electronic mail: kryv@fotonik.dtu.dk.

${ }^{h}$ Electronic mail: asryan@vt.edu.
}

the p-cladding layer and should effectively hamper the transport of electrons coming from the n-cladding layer. Hence, there will be ideally no holes in the part of the OCL confined between the n-side ABL and the n-cladding layer, as well as there will be no electrons in the part of the OCL confined between the p-side $\mathrm{ABL}$ and the p-cladding layer. As a result, the recombination current in the ABL laser will be purely due to recombination in the QW and the characteristic temperature will be the characteristic temperature of an ideal QW laser.

An InP-based laser structure with the barrier layer only in the $\mathrm{n}$-side of the active region (preventing the hole leakage out of QWs) was previously demonstrated. ${ }^{6}$ Though the threshold current density and the internal loss were lower as compared to a reference laser structure, the characteristic temperature improvement was rather moderate ( 62 vs. $57 \mathrm{~K}$ ). An InP-based laser structure with asymmetric barriers for both types of charge carriers was later proposed. ${ }^{7}$ It has been shown recently that the required asymmetry of electron and hole energy barriers can also be achieved in GaAs-based laser structures. ${ }^{8}$ However, there has been no experimental proof of the concept of ABL laser up to now.

In the present work, we report on the fabrication of a QW laser with ABLs and compare it to a conventional reference QW (CQW) laser (laser without ABLs). Both structures were grown by metal-organic chemical vapor deposition on $\mathrm{n}+$ GaAs (100) substrates. The schematic energy band diagrams of our CQW and ABL QW lasers are presented in Figs. 1(a) and 1(b), respectively. The offsets in the conduction and valence band edges shown in the figure were calculated in accordance with Ref. 9 taking into account the strain effects.

In the conventional laser, a $5 \mathrm{~nm}$-thick GaAs QW was grown in the middle of a $0.3 \mu$ m-thick undoped $\mathrm{Al}_{0.2} \mathrm{Ga}_{0.8} \mathrm{As}$ OCL clad by the $\mathrm{n}$ - and p-type $\mathrm{Al}_{0.4} \mathrm{Ga}_{0.6}$ As layers. The anticipated lasing wavelength was around $0.83 \mu \mathrm{m}$ (see below). In lasers of a similar design emitting at $0.85 \mu \mathrm{m}, T_{0}$ is about $100-110 \mathrm{~K}$ (see, e.g., Ref. 3). Because of shorter wavelength, i.e., smaller energy of carrier localization in a 
(a)

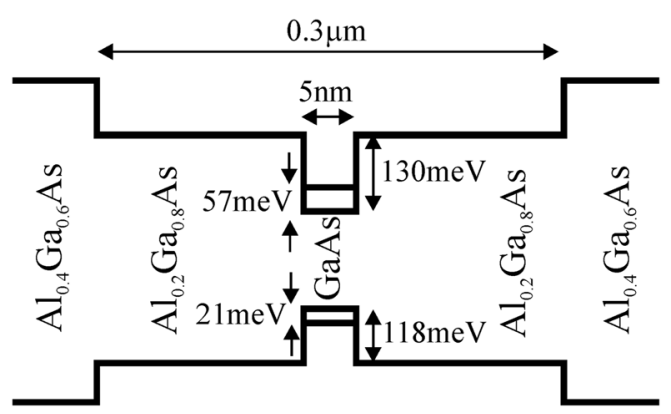

(b)

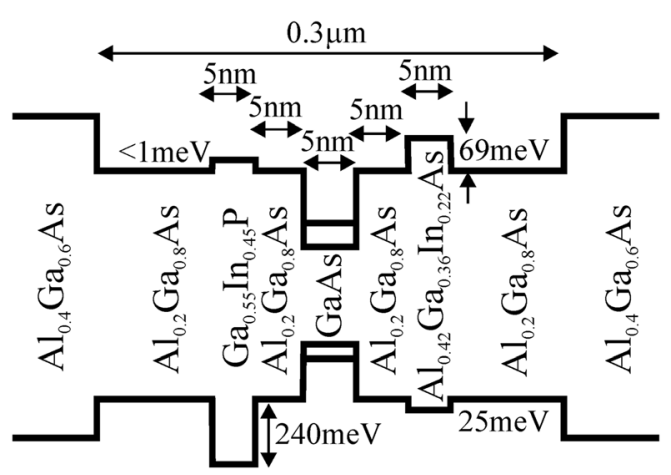

FIG. 1. Energy band diagrams of CQW laser (a) and ABL QW laser (b).

QW, we expect $T_{0}$ value below $100 \mathrm{~K}$ in the CQW laser of the present work. The ABL QW laser is distinct from the CQW laser, in that it comprises two additional asymmetric $5 \mathrm{~nm}$-thick barrier layers- one on each side of the QW. The materials of the ABLs located on the $n$ - and p-side of the QW are $\mathrm{Ga}_{0.55} \mathrm{In}_{0.45} \mathrm{P}$ and $\mathrm{Al}_{0.42} \mathrm{Ga}_{0.36} \mathrm{In}_{0.22} \mathrm{As}$, respectively. Each of the ABLs was separated from the QW by a $5 \mathrm{~nm}$ thick $\mathrm{Al}_{0.2} \mathrm{Ga}_{0.8} \mathrm{As}$ layer in order to facilitate the flux switches during the epitaxial growth process.

The compositions of the ABLs were chosen so that to provide as high as possible energy barriers for one type of charge carriers and as low as possible barriers for another type of charge carriers. The limitations of pseudomorphic growth mode and the requirement to avoid immiscibility in quaternary alloys were taken into consideration. The calculated energy barrier for holes at the $\mathrm{Ga}_{0.55} \operatorname{In}_{0.45} \mathrm{P} /$ $\mathrm{Al}_{0.2} \mathrm{Ga}_{0.8} \mathrm{As}$ heterojunction is $240 \mathrm{meV}$, whereas the barrier for electrons is estimated to be less than $1 \mathrm{meV}$. The barriers at the $\mathrm{Al}_{0.42} \mathrm{Ga}_{0.36} \mathrm{In}_{0.22} \mathrm{As}_{2} / \mathrm{Al}_{0.2} \mathrm{Ga}_{0.8} \mathrm{As}$ heterojunction are 69 and $25 \mathrm{meV}$ for electrons and holes, respectively.

The structures were processed into $100 \mu \mathrm{m}$-wide stripes with uncoated facets of different lengths. Both lasers demonstrated quite similar current-voltage characteristics with the turn-on voltage of about $1.5 \mathrm{~V}$ and the specific series resistance of about $8 \cdot 10^{-5} \Omega \cdot \mathrm{cm}^{2}$. The lasing wavelength of the ABL QW laser is slightly longer as compared with the CQW laser. For example, $2 \mathrm{~mm}$-long $\mathrm{ABL}$ laser diodes have the wavelength of $835.6 \mathrm{~nm}$ at $20^{\circ} \mathrm{C}$ as against $833.8 \mathrm{~nm}$ in the conventional laser diodes of the same length.

The threshold current density and the differential efficiency were measured in pulsed operation regime at various temperatures. Fig. 2 shows the temperature-dependence of the threshold current density in $0.5 \mathrm{~mm}$-long diodes for both laser structures in the $0-100^{\circ} \mathrm{C}$ temperature range. It is seen

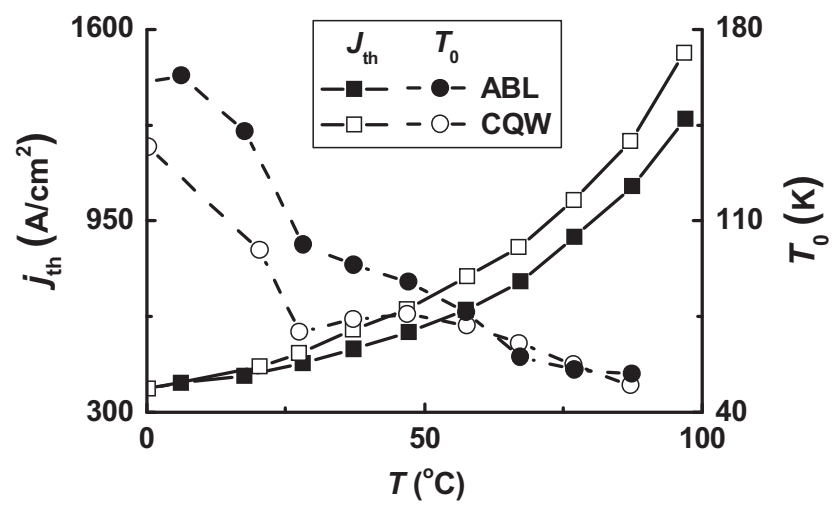

FIG. 2. Temperature dependence of the threshold current density (squares, left axis) and characteristic temperature (circles, right axis) for $0.5 \mathrm{~mm}$-long lasers. Dark symbols_ABL QW laser; open symbols_ CQW laser.

from the figure that the ABL laser is characterized by lower threshold current density as compared to its conventional counterpart. Below $0{ }^{\circ} \mathrm{C}$ (not shown in the figure), the threshold current densities of both lasers are nearly the same. A similar temperature behavior of the threshold current was observed for other cavity lengths $(0.25-2 \mathrm{~mm})$.

The characteristic temperature $T_{0}$ at a given temperature $T$ was calculated as

$$
T_{0}(T)=2 \Delta T /\left(\ln J_{t h}(T+\Delta T)-\ln J_{t h}(T-\Delta T)\right),
$$

where $J_{t h}(T \pm \Delta T)$ are the threshold current densities measured at temperatures slightly above and below $T$. It is evident from Fig. 2 that the ABL structure demonstrates higher $T_{0}$ in the $0-50{ }^{\circ} \mathrm{C}$ temperature range as compared to the CQW structure. The largest difference in $T_{0}$ values is $44 \mathrm{~K}(143 \mathrm{~K}$ in the $\mathrm{ABL}$ laser vs. $99 \mathrm{~K}$ in the $\mathrm{CQW}$ laser) and it is obtained at $20^{\circ} \mathrm{C} . T_{0}$ degrades noticeably in both structures as the laser cavity length decreases down to $0.25 \mathrm{~mm}$. Nevertheless, a higher $T_{0}$ in the ABL structure is quite remarkable for the entire range of the cavity length studied.

Fig. 3 depicts the reciprocal differential quantum efficiency, $1 / \eta_{d}$, as a function of the cavity length $L$ measured for both laser structures at 20 and $100^{\circ} \mathrm{C}$. For given $T$ and $L$, the ABL laser provides a higher efficiency as compared to the CQW laser. The internal quantum efficiency $\eta_{i n}$ and the

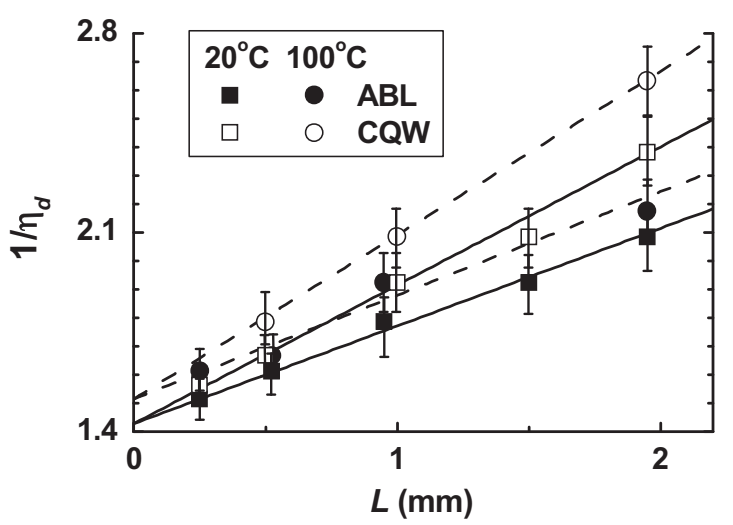

FIG. 3. Reciprocal differential quantum efficiency against cavity length measured at 20 (squares) and $100^{\circ} \mathrm{C}$ (circles). Dark symbols-ABL laser; open symbols-CQW laser. Linear fit: $20^{\circ} \mathrm{C}$ - solid lines; $100^{\circ} \mathrm{C}$-dashed lines. 


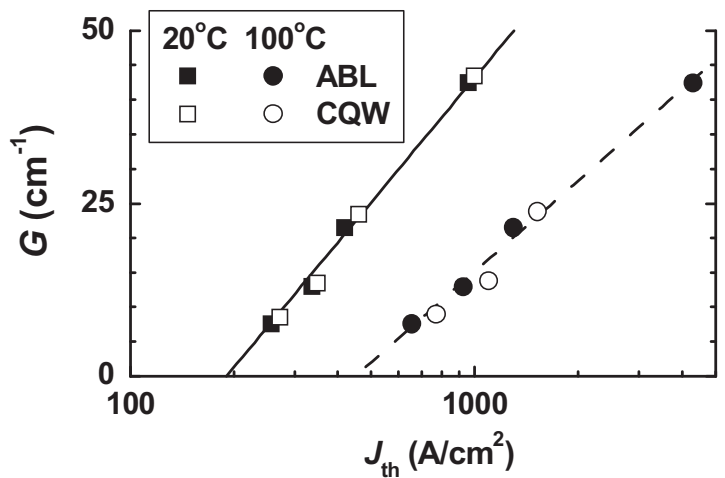

FIG. 4. Modal gain against threshold current density measured at 20 (squares) and $100^{\circ} \mathrm{C}$ (circles). Dark symbols-ABL laser; open symbolsCQW laser. Logarithmic fit: $20^{\circ} \mathrm{C}$-solid line; $100^{\circ} \mathrm{C}$-dashed line.

internal loss $\alpha_{\text {in }}$ were estimated by fitting the experimental data to the relationship

$$
1 / \eta_{d}=\left(1+\alpha_{i n} L / \ln (1 / R)\right) / \eta_{i n}
$$

where we put $\ln (1 / R) \approx 1$ ( $R$ is the facet reflectivity) for resonators with uncoated facets. We found that both structures are characterized by nearly the same internal quantum efficiency (0.7 and 0.66 at 20 and $100{ }^{\circ} \mathrm{C}$, respectively). However, the internal loss and its temperature behavior are improved in the ABL structure $\left(2.4 \pm 0.1 \mathrm{~cm}^{-1}\right.$ both at 20 and $\left.100^{\circ} \mathrm{C}\right)$, whereas $\alpha_{\text {in }}$ in the CQW structure increases from $3.4 \pm 0.1$ to $3.8 \pm 0.1 \mathrm{~cm}^{-1}$ as the temperature raises from 20 to $100^{\circ} \mathrm{C}$.

The modal gain at the lasing threshold was estimated for diodes of different lengths as the sum of the output loss [which is approximately equal to the reciprocal cavity length: $(1 / L) \ln (1 / R) \approx 1 / L]$ and the internal loss $\alpha_{\text {in }}$ (extracted from Fig. 3). Using the data for the threshold current density measured for different cavity lengths, we then plotted the estimated modal gain against threshold current density (shown at 20 and $100^{\circ} \mathrm{C}$ in Fig. 4). It is seen from the figure that both $\mathrm{ABL}$ and $\mathrm{CQW}$ lasers are characterized by nearly the same $G-J_{t h}$ relation, which can be approximated by the following logarithmic fit:

$$
G=G_{0} \ln \left(J_{t h} / J_{0}\right)
$$

where $G_{0}$ is the gain coefficient and $J_{0}$ is the transparency current density; both $G_{0}$ and $J_{0}$ are temperature-dependent. A reasonable agreement between the logarithmic fit and experimental data (both are shown in Fig. 4) is achieved if we use $G_{0}=26 \mathrm{~cm}^{-1}$ and $J_{0}=190 \mathrm{~A} / \mathrm{cm}^{2}$ at $20^{\circ} \mathrm{C}$, and $G_{0}=19 \mathrm{~cm}^{-1}$ and $J_{0}=450 \mathrm{~A} / \mathrm{cm}^{2}$ at $100^{\circ} \mathrm{C}$. At a given temperature, $G_{0}$ and $J_{0}$ are the same for the ABL and CQW lasers.

The effect of reduced internal loss in the ABL laser (as compared to the CQW laser) on the threshold current density can be estimated from Eq. (3) as follows:

$$
J_{t h}^{\mathrm{ABL}} / J_{t h}^{\mathrm{CQW}} \approx 1-\left(\alpha_{i n}^{\mathrm{CQW}}-\alpha_{i n}^{\mathrm{ABL}}\right) / G_{0} .
$$

At $100{ }^{\circ} \mathrm{C}$, the internal loss difference between the CQW and ABL lasers is $\alpha_{i n}^{\mathrm{CQW}}-\alpha_{i n}^{\mathrm{ABL}}=1.4 \mathrm{~cm}^{-1}$, and we obtain from Eq. (4) that $J_{t h}^{\mathrm{ABL}} / J_{t h}^{\mathrm{CQW}} \approx 0.93$. The experimental value of the ratio $J_{t h}^{\mathrm{ABL}} / J_{\text {th }}^{\mathrm{CQW}}$ at $100{ }^{\circ} \mathrm{C}$ (obtained from Fig. 2) is, however, 0.85 . We suggest that a lower actual ratio $J_{t h}^{\mathrm{ABL}} / J_{t h}^{\mathrm{CQW}}$ is due to a partial suppression of parasitic recombination current in the OCL of the ABL laser. Suppression of parasitic recombination can improve the temperature-stability of the threshold current (especially at elevated temperatures), since the temperature-dependence of the recombination current in the OCL is described by a considerably lower $T_{0}$ as compared to the recombination current in the QW (see Eqs. (21) and (22) in Ref. 8).

As already discussed, ideally there should be no bipolar carrier population in the OCL of the ABL laser (except for thin regions adjoining the $\mathrm{QW})$. In such an ideal $\mathrm{ABL}$ laser, the calculated ratio $J_{\text {th }}^{\mathrm{ABL}} / J_{\text {th }}^{\mathrm{CQW}}$ should be less than $1 / 3$ and the characteristic temperature should be about $220 \mathrm{~K}^{8} \mathrm{We}$ suggest that the difference between the characteristics of our experimental laser and the ideal ABL laser may be due to the fact that the barrier $(69 \mathrm{meV})$ provided in the conduction band by the $\mathrm{p}$-side $\mathrm{ABL}\left(\mathrm{Al}_{0.42} \mathrm{Ga}_{0.36} \mathrm{In}_{0.22} \mathrm{As}\right)$ in the experimental structure is not high enough to prevent the electron injection to the p-side of the OCL. As a result, a bipolar population may still exist and parasitic electron-hole recombination may occur in the p-side of the OCL.

In conclusion, an AlGaAs/GaAs QW laser structure, which comprises additional asymmetric barriers $\left(\mathrm{Ga}_{0.55} \mathrm{In}_{0.45} \mathrm{P}\right.$ and $\left.\mathrm{Al}_{0.42} \mathrm{Ga}_{0.36} \mathrm{In}_{0.22} \mathrm{As}\right)$ between the $\mathrm{n}$ - and p-sides of the OCL and QW, has been fabricated and tested. Compared to the conventional reference QW laser, our ABL QW laser demonstrates reduced threshold current and increased characteristic temperature. In addition, the ABL laser is characterized by lower and less temperature-sensitive internal optical loss.

This work was supported by the Federal Target Program "Scientific and Scientific-Pedagogical Personnel of Innovative Russia" (arrangement no. 1.5 "Team research led by invited scientists," Grant No. 02.740.11.5161) and in part by Grant No. 274-09-0247 (FLASH) from the Danish Council for Independent Research. E.S.S. also acknowledges the European Commission for funding through the Marie Curie Incoming International Fellowship (Project No. 252890).

${ }^{1}$ Y. Arakawa and H. Sakaki, Appl. Phys. Lett. 40, 939 (1982).

${ }^{2}$ J. J. Lee, L. J. Mawst, and D. Botez, J. Cryst. Growth 249, 100 (2003).

${ }^{3}$ M. Dion, Z.-M. Li, D. Ross, F. Chatenoud, R. L. Williams, and S. Dick, IEEE J. Sel. Top. Quantum Electron. 1, 230 (1995).

${ }^{4}$ H. Kurakake, T. Uchida, T. Yamamoto, T. Higashi, S. Ogita, and M. Kobayashi, IEEE J. Sel. Top. Quantum Electron. 3, 632 (1997).

${ }^{5}$ L. V. Asryan and S. Luryi, Solid-State Electron. 47, 205 (2003).

${ }^{6}$ S. Hausser, H. P. Meier, R. Germann, and Ch. S. Harder, IEEE J. Quantum Electron. 29, 1596 (1993).

${ }^{7}$ L. V. Asryan and S. Luryi, U.S. patent 6,870,178 (2005).

${ }^{8}$ L. V. Asryan, N. V. Kryzhanovskaya, M. V. Maximov, A. Yu. Egorov, and A. E. Zhukov, Semicond. Sci. Technol. 26, 055025 (2011).

${ }^{9}$ M. P. C. M. Krijn, Semicond. Sci. Technol. 6, 27 (1991). 